\title{
RANCANG BANGUN STARTING MOTOR INDUKSI 3 FASA HUBUNG BINTANG SEGITIGA DILENGKAPI PENGAMAN 3 FASA BERBASIS MIKROKONTROLER ATMEGA8535
}

\author{
Sujarot, Abdul Haris, Agus Trisanto \\ Jurusan Teknik Elektro Fakultas Teknik Universitas Lampung
}

Ir.djarot@yahoo.co.id, aharis@unilla.ac.id, at@unilla.ac.id

\begin{abstract}
Abstrak
Motor induksi 3 fasa pada industri besar merupakan sebuah peralatan yang sangat penting, mengingat kontruksi dan perawatannya yang sederhana dan relative tidak ada biaya pemeliharaan karena tidak menggunakan komutator dibanding penggerak penggerak yang lain seperti motor bakar. Perlindungan terhadap peralatan saat ini semakin ditingkatkan agar keandalan sistem dapat terpenuhi. Pengaman motor induksi 3 fasa adalah salah satu pengaman yang digunakan untuk melindungi motor induksi 3 fasa dari hubung singkat kumparan dan mengakibatkan terbakarnya belitan. Pada motor induksi 3 fasa dengan kapasitas daya yang besar memiliki arus starting yang besar saat ini masih menggunakan timer yang sifat kerjanya tetap tidak sesuai kondisi sistem saat itu. Dari dua permasalahan diatas dapat dilakukan penyelesaian dengan menggunakan mikrokontroler, yaitu dengan cara mendeteksi arus nominal motor sebagai acuan peralihan dari bintang ke segitiga. Pemasangan trafo tegangan pada masing masing fasa digunakan sebagai inputan mikrokontroler yang akan mengendalikan suplay 3 fasa disaat starting. Dari data hasil pengujian peralatan dapat diperoleh apabila salah satu fasa pada masukan motor induksi 3 fasa tidak terdeteksi maka proses starting motor induksi 3 fasa tidak dapat berjalan, hubung bintang segitiga dari data yang diperoleh memiliki penurunan arus starting hingga 1/3. Starting dengan acuan arus nominal motor induksi 3 fasa saat itu dapat mengoptimalkan torque.
\end{abstract}

Kata kunci : starting motor induksi 3 fasa hubung bintang( $\mathrm{Y})$ - segitiga $(\Delta)$, serta pengaman 3 fasa. Mikrokontroler.

\begin{abstract}
Abstrak
3-phase induction motors in the industry is a very important equipment, given the construction and maintenance is simple and relatively no maintenance costs as compared to not using a commutator mover such as motor fuel. The protection of the equipment is now getting upgraded so that the system reliability can be met. Safety of 3 phase induction motor is one of the safeguards used to protect three-phase induction motor from short circuit and cause burning coil windings. In 3-phase induction motor with a power capacity has great large starting currents today still use the timer still does not fit the nature of his condition of the system at that time. Of the two problems above can be done using a microcontroller settlement, that is by detecting the motor nominal current as the reference transition from star to triangle. Installation of transformer voltage on each phase is used as an input microcontroller that will control 3 phase suply when starting.From the data of the test equipment can be obtained if one phase to 3 phase induction motor input is not detected then the starting of 3 phase induction motor can not run, triangular star circuit of the data obtained had a reduced starting currents up to $1 / 3$. Starting with reference to the nominal current of 3 phase induction motor as it can optimize torque.
\end{abstract}

Keywords: 3-phase induction motor starting circuits stars $(\mathrm{Y})$ - triangle $(\Delta)$, as well as 3-phase safety. Microcontroller

\section{PENDAHULUAN \\ A. Latar Belakang}


Motor induksi 3 fasa merupakan peralatan yang sangat penting dalam dunia industri. Motor induksi 3 fasa adalah sebuah instrumen listrik yang berfungsi untuk mengubah energi listrik menjadi energi mekanik, prinsip kerjanya adalah berdasarkan prinsip induksi elektromagnetik. Motor induksi 3 fasa memiliki banyak macam dan jenisnya terutama pada motor-motor induksi yang berdaya besar. Motor induksi 3 fasa yang memiliki daya besar, tentu memiliki perbedaan starting dengan motor yang berdaya kecil. Untuk itu, motor induksi yang memiliki daya besar membutuhkan supply daya yang besar dalam proses pengoperasian awal, kondisi ini tentu mempengaruhi kondisi sitem hal ini dapat dikurangi dengan melakukan starting motor induksi tidak secara langsung, yaitu dengan metode hubung bintang segitiga. Motor induksi yang digunakan pada industri besar merupakan motor yang memiliki daya di atas $2.25 \mathrm{KW}$, sehingga konsumsi daya yang besar disaat starting dengan kondisi motor induksi beban penuh. Permasalahan ini yang menjadi pemikiran pentingya starting dengan menggunakan hubung bintang ( $\mathrm{Y}$ ) ke segitiga $(\Delta)$.

\section{B. Tujuan}

Tujuan dari penelitian yang dilakukan adalah :

1. Merancang bangun starting motor induksi 3 fasa dengan menggunakan hubung bintang( $\mathrm{Y}$ )segitiga $(\Delta)$ dilengkapi pengaman 3 fasa berbasis Mikrokontroler ATmega8535.

2. Membuat starting hubung bintang ke segitiga sesuai dengan kondisi arus nominal motor induksi 3 fasa.

\section{Manfaat}

Adapun manfaat yang diharapkan dapat tercapai, dalam penelitian ini adalah sebagai berikut :

1. Dapat digunakan sebagai salah satu pertimbangan dalam perancangan mesin listrik yang menggunakan motor induksi 3 fasa dengan kapasitas daya yang besar.

2. Menghasilkan sebuah alat yang dapat digunakan dalam starting motor induksi 3 fasa yang dilengkapi dengan pengaman 3 fasa.

3. Sebagai referensi untuk penelitian berikutnya yang membahas mengenai starting motor induksi 3 fasa.

4. Menghasilkan starting hubung bintang - segitiga yang sesuai dengan arus nominal motor induksi 3 fasa disaat starting.

\section{Rumusan Masalah}

Metode starting motor induksi 3 fasa yang sering digunakan, adalah starting menggunakan timer yang memiliki tingkat peralihan berdasrkan waktu yang bersifat permanen, kondisi ini tanpa dipengaruhi kondisi sistem saat itu. Timer yang digunakan hanya bekerja sesuai dengan pengaturan waktu ketika awal, hal ini tentu kurang efektif mengingat kondisi sistem tidak selalu tetap, sehingga mempengaruhi proses peralihan dari bintang segitiga.

\section{E. Batasan Masalah}

Ada beberapa hal yang menjadi batasan masalah dalam tugas ahir ini adalah :

1. Menggunakan motor induksi 3 fasa dengan kapasitas $1 \mathrm{KW}$

2. Sistem pengendalian utama menggunakan mikrokontroler ATmega8535.

3. Menggunakan pengaman 3 fasa disaat starting awal.

4. Dalam menguji arus starting motor induksi 3 fasa tidak dilakukan pemvariasian beban.

\section{F. Hipotesis}

Starting yang dilakukan menggunakan hubung bintang $(\mathrm{Y})-\operatorname{segitiga}(\Delta)$ dengan menggunakan ATmega8535 diharapkan dapat mengendalikan kondisi starting dari motor induksi 3 fasa ketika bekerja, waktu perpindahan bintang ke segitiga dapat terjadi secara tepat, kondisi ini tercapai ketika sensor arus yang ada pada fasa $\mathrm{S}$ yang sesuai dengan arus nominalnya, kemudian akan dilakukan pemprosesan di ATmega8535. Waktu yang dibutuhkan dapat dengan tepat sesuai dengan kondisi arus nominalnya.

\section{TINJAUAN PUSTAKA}

\author{
A. Hubung Bintang( Y ) - Segitiga( $\Delta$ ) Pada \\ Motor Induksi 3 Fasa
}


Pengaturan starting hubung bintang - segitiga digunakan untuk mengurangi arus starting yang besar ketika motor induksi 3 fasa mulai bekerja. Untuk motor induksi 3 fasa yang dihubungan secara langsung yaitu motor-motor yang memiliki daya di bawah $2.25 \mathrm{KW}$ tidak perlu menggunakan metode hubung bintang- segitiga atau metode metode starting yang lainnya, hal ini dikarenakan arus starting yang ada pada motor tersebut relative kecil sehingga tidak mengganggu kondisi sistem saat itu, namun pada motor yang memiliki daya besar seperti daya $5 \mathrm{KW}$ sampai $50 \mathrm{KW}$ sangat penting dalam perancangan kendali motor induksi 3 fasa yang digunakan, salah satunya dengan menggunakan hubung bintang segitiga.

Hubung Bintang ( $\mathrm{Y}$ ).

$I s_{t}=\frac{V}{\sqrt{3} / Z} /$ fasa

$Z=R+J X$

Keterangan

Ist $=$ Arus start $(A)$

$V=$ Tegangan $(V)$

$Z=$ Impedansi ( $\Omega$ )

$X=$ Reaktansi $(\Omega)$

Hubung segitiga ( $\Delta)$.

$I_{s t / f a s a}=\frac{1}{\sqrt{3}} \cdot I_{L-L}$

$I_{L}=\frac{\sqrt{3} V}{Z}$

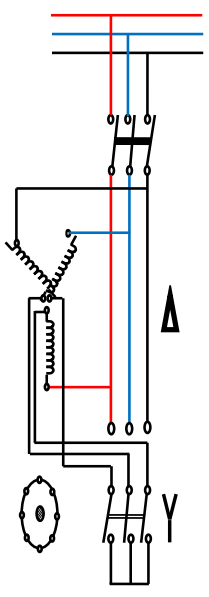

Gambar 1. Rangkaian $\mathrm{Y} / \Delta$
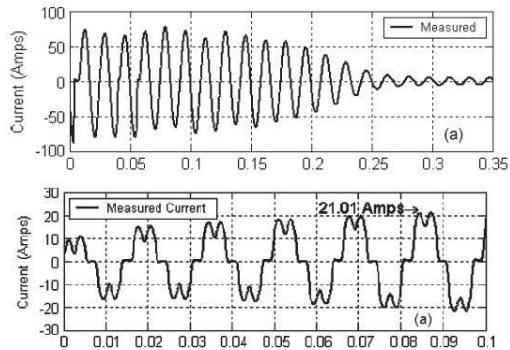

\section{Gambar 2. karakteristik starting motor induksi 3 fasa}

\section{B. Motor induksi 3 Fasa}

Motor induksi 3 fasa merupakan sebuah perangkat elektromagnetis yang mengubah energi listrik menjadi energi mekanik. Energi mekanik ini digunakan untuk memenuhi kebutuhan sehari-hari, misalnya, memutar impeller pompa, fan atau blower, menggerakan kompresor, memindahkan barang dari satu tempat ke tempat yang lain dan masih bannyak lagi fungsi dari motor induksi.
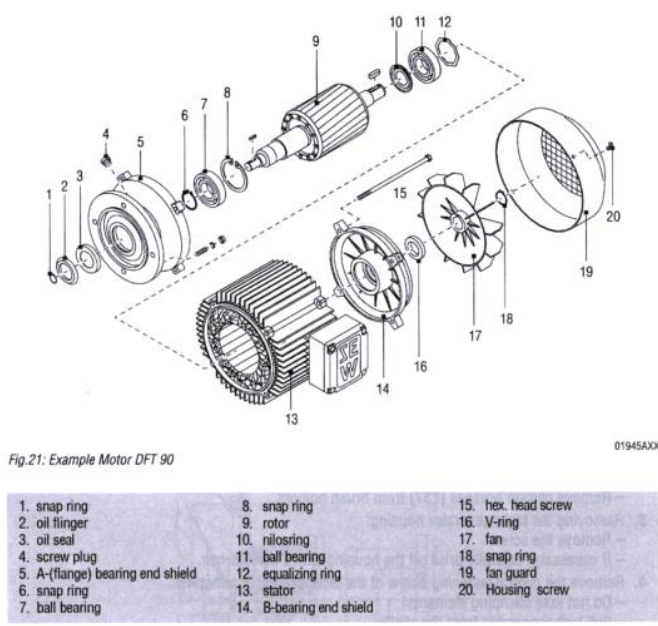

Gambar 3. Motor Induksi 3 Fasa

\section{METODE PENELITIAN}

\section{A. Waktu dan Tempat}

Penelitian dan perancangan tugas akhir dilakukan di Laboratorium Terpadu Teknik Elektro Universitas Lampung mulai dilaksanakan Bulan April 2011 dan direncanakan selesai pada Bulan Desember 2011 


\section{Spesifikasi Rancangan}

Secara garis besar sistem pada tugas akhir ini adalah seperti gambar di bawah ini :

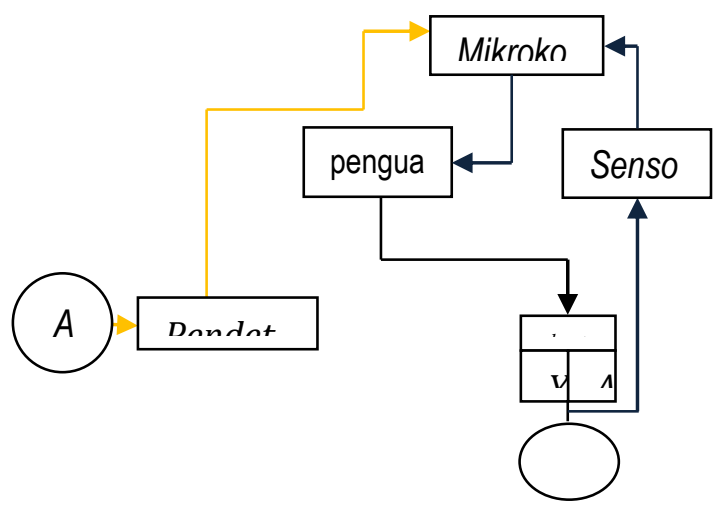

Gambar 4. Blok Diagram

\section{Pengujian Alat}

Pengujian dari hasil perancangan pengendali bintang segitiga dilengkapi pengaman 3 fasa pada motor induksi 3 fasa menggunakan pengendali elektronik, dilakukan pada masing-masing bagianya yaitu pada rangkaian dan program. Pada pengujian perangkat keras dilakukan pengujian per-blok rangkaian, dan pengujian secara keseluruhan. Pengujian per-blok bertujuan agar kesalahan pada rangkaian dapat diketahui apakah masing-masing bagian dari rangkaian dapat berfungsi dengan baik sebagaimana mestinya. Sedangkan pengujian keseluruhan dimaksudkan, untuk mengetahui apakah hasil dari perancangan yang telah selesai pengerjaannya dapat bekerja dengan baik sesuai dengan spesifikasi, dan rancangan dari alat tersebut.

\section{HASIL DAN PEMBAHASAN}

\section{A. Realisasi Perancangan Dan Pengujian Alat}

Realisasi perancangan alat dan pengujian dibagi menjadi dua bagian yaitu realisasi perancangan perangkat keras dan realisasi perancangan dan pengujian perangkat lunak perbagian maupun secara keseluruhan.

\section{Realisasi Perangkat Keras}

Pada starting motor induksi 3 fasa hubung bintang segitiga dilengkapi pengaman 3 fasa, terdapat beberapa perangkat keras yang mendukung sistem kerja alat, terutama sistem kerja pada mikrokontroler ATMega8535, sistem peralihan dari hubung bintang ke segitiga maupun pendeteksi adanya sumber 3 fasa dari sumber 3 fasa.

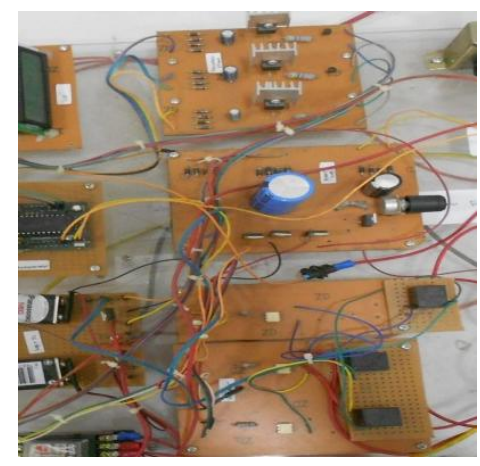

Gambar 5. Rangkaian Actuator

\section{2c. Pengujian Trafo Tegangan Yang dikonversi ke Arus}

Pengujian ini dilakukan dengan melakukan pengukuran pada tegangan keluaran disisi sekunder trafo maupun disisi primer sehingga dapat terlihat ketika tegangan pada sisi primer trafo mengalami penurunan maka tegangan pada sisi skunder pun akan secara automatis turun. Pada sisi primer trafo tegangan dipengaruhi oleh besarnnya arus yang mengalir pada sisi primer, pada sisi primer trafo disusun secara seri dengan beban motor induksi 3 fasa. Sehingga arus yang mengalir pada sisi primer akan mempengaruhi besarnya tegangan primer dan sekunder pada trafo tegangan. Seperti terlihat pada tabel di bawah ini :

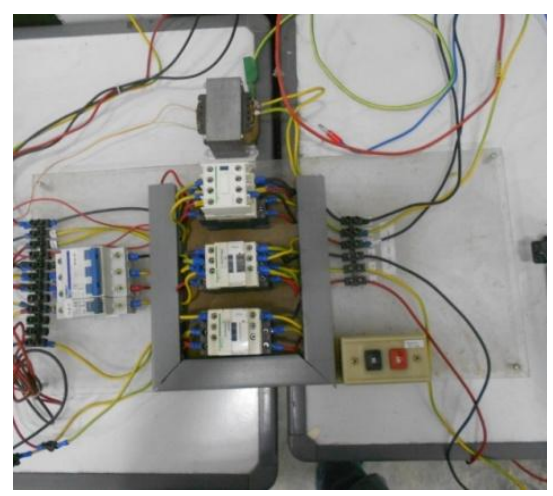

Gambar 6. Trafo Tegangan 


\section{Rangkaian Pendeteksi Sumber 3 Fasa}

Pada rangkaian ini digunakan transformator 3 fasa yang akan mendeteksi masing-masing fasa pada sumber tiga fasa, ketika masing-masing trafo 1 fasa mendapat sumber 3 fasa maka transistor 2n3904, pada dasarnya apabila transistor pada kaki base mendapat trigger arus sehingga electron pada transistor akan bergerak. Transistor bekerja maka collector dan emitter berada dalam kondisi satu rasi sehingga tegangan $\mathrm{V}_{\mathrm{CE}}$ adalah nol volt ketika kondisi di atas harus terpenuhi

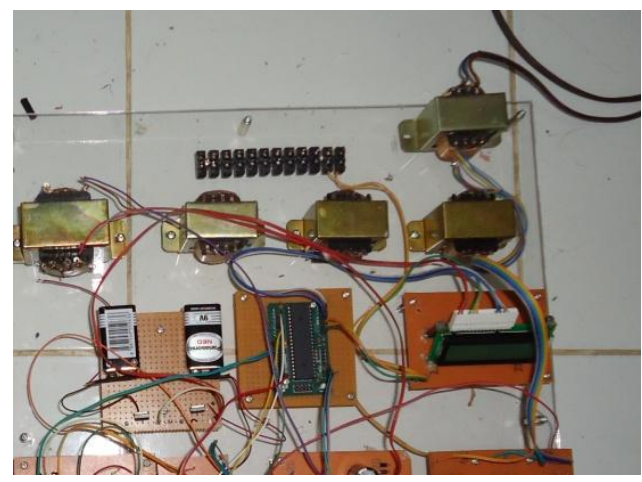

Gambar 7. Pendeteksi Sumber 3 Fasa

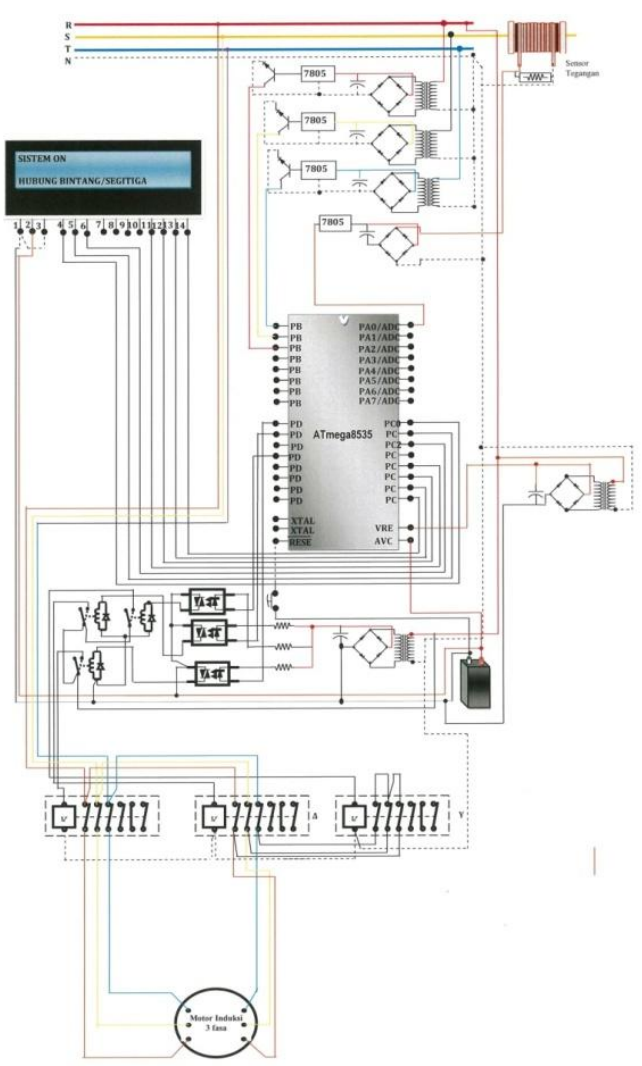

Gambar 8. Skematik kendali Y/A dilengkapi pengaman 3 fasa

Pada gambar diatas merupakan rangkaian skematik starting hubung bintang ke segitiga dilengkapi pengaman 3 fasa. Proses starting hubung bintang ke segitiga yang dilengkapi pengaman 3 fasa, bekerja apabila masing masing trafo 1 fasa, yang terpasang pada setiap fasa mendapat supply untuk memberi tegangan pada transistor 2N3904 sehingga transistor bekerja bekerjannya transistor akan memberikan masukan low pada mikrokontroler. Apabila salah satu fasa pada trafo tidak bekerja maka proses starting motor induksi 3 fasa tidak berjalan program yang ada pada mikrokontroler berhenti sampai perintah awalnya hal ini terjadi karena tiga iputan low pada mikrokontroler tidak terpenuhi.

Ketika kondisi di atas terpenuhi maka proses selanjutya dapat berjalan yaitu starting hubung bintang ke segitiga, proses perpindahan ini dapat berjalan apabila ADC mikrokontroler bekerja sesuai dengan program yang telah dibuat, yaitu ketika port A pin 0 mendapat masukan tegangan $<=4.2$ Volt, nilai ini terbaca pada ADC 215, pada kondisi ini berada pada hubung segitiga, sehingga apabila nilai 
masukan tegangan pada port A pin $0>4.2-5$ volt maka sistem berada pada hubung bintang. Tegangan maksimum pada masukan di port $\mathrm{A}$ adalah sebesar 5 volt.

Pada gambar 32. Kontaktor utama dan kontaktor bintang bekerja secara bersamaan disaat starting awal, dan disaat arus nominal pada motor telah tercapai maka kontaktor segitiga bekerja, dalam kondisi ini kontaktor utama tetap bekerja dan kontaktor bintang mati. Kontaktor akan bekerja apabila masing masing relay bekerja ketika mendapat masukan dari optocopler yang diperintahkan oleh mikrokontroler, maka kontaktor magnit akan bekerja apabila relay telah bekerja terlebih dahulu sehingga arus listrik dapat mengalir pada coil kontaktor magnit. Dan selanjutnya untuk proses pennonaktifan yaitu dengan menekan tombol off pada saklar, dalam kondisi ini maka semua rangkaian sudah dalam kondisi tidak bertegangan.

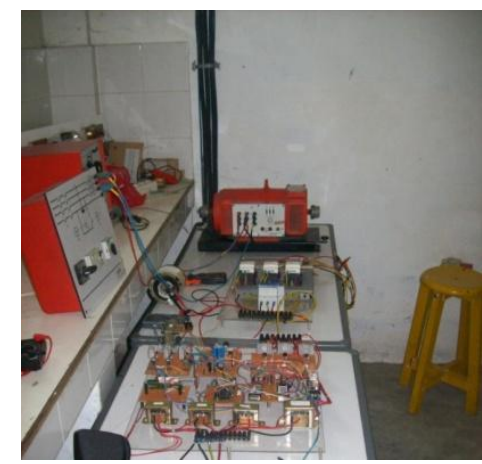

Gambar 35. Realisasi Alat Rancang Bangun Starting Motor Induksi 3 Fasa

Hubung Bintang - Segitiga Dilengkapi Pengaman 3 Fasa Berbasis

Mikrokontroler ATmega8535.

Tabel 4. Arus Nominal dan Arus Starting Motor Induksi 3 Fasa $1 \mathrm{KW}$

\begin{tabular}{|l|l|c|c|c|}
\hline \multicolumn{5}{|c|}{ Pengujian Berbeban } \\
\hline $\begin{array}{l}\text { Vsumbe } \\
\text { r(V) }\end{array}$ & $\begin{array}{l}\text { Vsumber } \\
(V)\end{array}$ & Arus & Aru & Wakt \\
Fasa - & & & & $u$ \\
Fasa & Fasa $-N$ & $(A)$ & $(A)$ & $(S)$ \\
\hline 380 & 220 & 2 & 1.2 & 1 \\
\hline
\end{tabular}

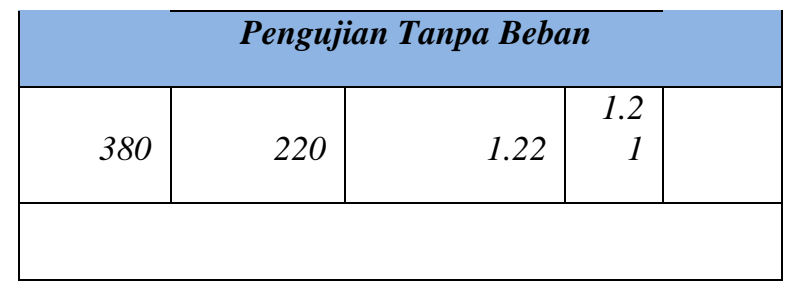

Pada tabel di atas tegangan sumber yang diberikan dalam kondisi yang normal, ketika motor induksi 3 fasa starting arus yang mengalir adalah sebesar 2 (A) dan disaat beban sudah dalam kondisi konstan maka arus yang mengalir pada motor induksi 3 fasa adalah sebesar 1,21 (A), pada kondisi ini adalah kondisi peralihan dari bintang ke segitiga. Besarnya arus 1,21 menjadi patokan proses peralihan dari bintang ke segitiga mengingat nilai ini merupakan nilai nominal disaat motor induksi 3 fasa starting. Ketika motor induksi 3 fasa dikondisikan tidak berbeban maka besarnya arus yang mengalir pada motor induksi adalah sebesar 1,21 (A), dalam kondisi ini nilainya tidak mengalami perubahan, kondisi ini terjadi karena motor induksi dalam kondisi tidak berbeban.

\section{SIMPULAN DAN SARAN}

\section{A. Simpulan}

Berdasarkan pengamatan dan pengujian alat secara keseluruhan maupun perbagian dapat diperoleh kesimpulan sebagai berikut :

1. Dengan adanya pengaman 3 fasa sebelum dilakukan pengoperasian, menghindarkan motor induksi 3 fasa bekerja dalam kondisi 1 fasa atau 2 fasa, sehingga kopel motor induksi 3 fasa tidak berkurang disaat starting.

2. Waktu perpindahan dari bintang - segitiga dapat lebih tepat, sesuai arus nominalya.

3. Metode hubung bintang ke segitiga dapat mengurangi arus starting motor induksi 3 fasa hingga $1 / 3$.

4. Besarnya arus yang mengalir pada kumparan primer trafo tegangan berbanding terbalik dengan tegangan.

5. Kondisi motor induksi 3 fasa berbeban atau tidak sangat mempengaruhi arus starting. 


\section{B. SARAN}

1. Sebaiknya perlu dilakukan pengoptimalan fitur fitur yang ada pada mikrokontroler untuk diaplikasikan pada motor induksi 3 fasa.

2. Perlunya pengujian mengenai peralatan peralatan elektronika yang digunakan sebagai peralatan pendukung dalam tugas ahir ini agar dapat diketahui tingkat keandalannya dalam jangka panjang.

3. Penggunaan sensor kecepatan yang digunakan sebagai acuan peralihan dari bintang ke segitiga.

\section{DAFTAR PUSTAKA}

[1] Rasid, Muhammad H. 1999. Elektronika Daya jilid 1. PT. Prenhallindo. Jakarta.

[2] Daryanto.2004.Pengetahuan Teknik Elektronika.PT. Bumi Aksara. Jakarta.

[3] Theraja.A.k.Theraja.BL.T.1999.electrical technology.S Chend \& company. New Delhi.

[4] Wardhana, Lingga. 2006. Belajar Sendiri Mikrokontroler Seri ATmega8535. Penerbil Andi. Yogyakarta.

[6] Winoto, Ardi. 2010. Mikrokontroler AVR ATmega8/16/32/8535 dari pemprogramannya dengan bahasa $\mathrm{C}$ pada win AVR. Penerbit Informatika. Bandung.

[7] paul Malvino, Albert. 2003. Prinsip-prinsip Elektronika. Penerbit Salemba Teknika.

[8] Muhammad Dwi Kurniawan, Aris Kurniawan. Starting motor induksi 3 fasa dengan metode $\mathrm{Y} / \Delta$ menggunakan mikrokontroler AT89C31. Institut Sepuluh November. Surabaya. www.digilib.itb.ac.id akses tanggal 10 Mei 2012

[9] http://id.wikipedia.org/wiki/motor listrik 3 F 10 Maret 2012

[10] http:/IEE.com starting Motor induksi 3 fasa Januari 2012

[11] http://id.wikipedia.org/wiki/Triac 10 maret $\underline{2011}$

Starting motor $3 \mathrm{~F}$

[12] http:// www.4shared.com/ starting motor Induksi 12 Maret 2011

All datasheet 